\title{
Study of the Complex Stiffness of a Vibratory Mechanical System with Shape Memory Alloy Coil Spring Actuator
}

\author{
Samuell A. Holanda, ${ }^{1}$ Antonio A. Silva, ${ }^{1}$ Carlos J. de Araújo, ${ }^{1}$ and Alberdan S. de Aquino ${ }^{2}$ \\ ${ }^{1}$ Federal University of Campina Grande (UFCG), 58420-140 Campina Grande, PB, Brazil \\ ${ }^{2}$ Federal Institute of Paraíba (IFPB), 58015-430 João Pessoa, PB, Brazil \\ Correspondence should be addressed to Antonio A. Silva; almeida@dem.ufcg.edu.br
}

Received 15 July 2013; Accepted 3 March 2014; Published 18 June 2014

Academic Editor: Miguel M. Neves

Copyright (c) 2014 Samuell A. Holanda et al. This is an open access article distributed under the Creative Commons Attribution License, which permits unrestricted use, distribution, and reproduction in any medium, provided the original work is properly cited.

\begin{abstract}
The vibration control is an important area in the dynamic of structures that seeks to reduce the amplitude of structural responses in certain critical frequency ranges. Currently, the scientific development leads to the application of some actuators and sensors technologically superior comparing to the same features available on the market. For developing these advanced sensors and actuators, smart materials that can change their mechanical properties when subjected to certain thermomechanical loads can be employed. In this context, Shape memory alloys (SMAs) may be used for developing dynamic vibration dampers which are capable of acting on the system providing proper tuning of the excitation frequency and the natural frequency. This paper aims to analyze the behavior of the stiffness and damping of a SMA helical coil spring actuator coupled to a mechanical system of one degree of freedom (1 DOF) subjected to an unbalanced excitement force and a temperature control system. By analyzing the effect of these parameters on the structural response and considering the concept of complex stiffness, it can be possible to predict the system's behavior within certain acceptable ranges of vibration, already in the design phase.
\end{abstract}

\section{Introduction}

In the current stage of scientific and technological development, design of structures becomes increasingly complete and comprehensive to meet the diverse performance requirements. Among these requirements, we highlight the need for increasingly lighter and resilient structures, dynamic behavior to ensure stability and accuracy, and attenuation of vibrations to ensure the structural integrity and better comfort [1].

Structural systems are constantly susceptible to excitations that can lead to mechanical vibrations. These vibrations are in most cases undesirable, because they can endanger the structural integrity of the system itself and, in some cases, the safety of users.

Recently, shape memory alloys (SMA) appear as potentially viable actuators for vibration control. The shape memory effect, superelasticity, and changes of mechanical properties with temperature allow the application of these smart materials in various fields of engineering [2]. However, the behavior of SMA is nonlinear, which makes its modeling and numerical simulation more complex, since the changes of parameters such as temperature and excitation frequency should be considered. This behavior requires further study to determine the intrinsic characteristics of SMA such as complex stiffness, which considers the energy dissipation per cycle and the frequency dependence that lead to variations of the structural damping.

The natural frequency depends on the mass and stiffness of a mechanical system and SMA has the capacity to alter the elastic modulus. Then, employing these smart materials, it is possible to change the stiffness of a mechanical system and consequently change resonance regions. Some studies indicate that this effect can attenuate the amplitude of vibrations in a critical frequency range for making the transition for resonance; it also allows changing the vibration modes of the structure [3].

SMAs are naturally classified as metallic materials with high damping capacity, consequence of a hysteretic behavior related to phase transformations of the material $[2,3]$. 
The damping factor of the system also changes with the change of stress or temperature of the SMA actuator. However, the influence of damping vibration levels and system response, due to a change in the SMA behavior, needs to be further investigated and understood [4]. In many cases, for vibration attenuation, SMAs are used in the form of helical coil springs $[3,5-10]$.

Very recently, Aguiar et al. [5] realized an experimental investigation of vibration reduction using SMA springs. The vibration analysis revealed that SMA elements introduce complex behaviors to the studied system and that different thermomechanical loadings are of concern showing the main aspects of the SMA dynamical response. The results establish that adaptability due to temperature variations is defined by a competition between stiffness and hysteretic behavior changes. In another recent work, Aguiar et al. [6, 7] studied specifically the modeling, simulation, and experimental analysis of SMA helical springs. Basically, it is assumed that a one-dimensional constitutive model to describe its thermomechanical shear behavior and, afterwards, helical springs are modeled by considering classical approach. Savi et al. [8] investigated the nonlinear dynamics of an adaptive tuned vibration absorber (ATVA) with a SMA element. The influence of the hysteretic behavior due to stress-induced phase transformation of the SMA is considered. The hysteretic behavior introduces complex characteristics to the system dynamics but also changes the absorber response allowing vibration reduction in different frequency ranges.

SMA springs were investigated by Rackza [9] on a structure of controllable-stiffness springs which might be utilized in vibration reduction systems, for example, in driver seats. Mirzaeifar et al. [10] studied analytically and numerically the pseudoelastic response of SMA helical springs under axial force. Analytical and numerical results are compared and it is shown that the solution based on the SMA curved bar torsion gives an accurate stress analysis in the cross section of the helical SMA spring in addition to the global load-deflection response. Toi et al. [11] proposed a finite element formulation for the analysis of superelastic behaviors of SMA helical spring considering the asymmetric tensile and compressive behavior and the torsional deformation. The developed program has applied to the superelastic, large deformation analysis of NiTi helical springs under tensile loading and unloading.

In this paper, the effects of stiffness and damping of a SMA helical spring actuator on the dynamic response of a mechanical system of one degree of freedom (1 DOF) subjected to free vibration and harmonic excitation from an unbalanced motor were studied. The main objective is to introduce the concept of complex stiffness in a mechanical system incorporating SMA, not explored in the aforementioned works.

\section{Model of Unbalanced Rotating and Complex Stiffness}

The studied mechanical system is excited harmonically through a motor with unbalanced rotating. This condition can be simplified and better understood from the model

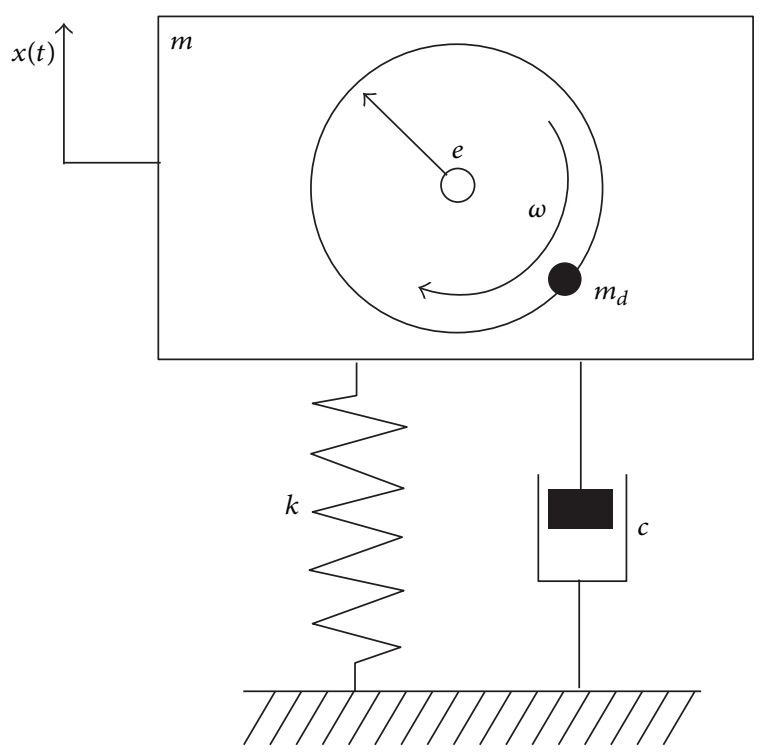

FIGURE 1: Physical model of unbalanced rotating system with one SMA coil spring $(k, c)$.

of rotating unbalanced machines, illustrated in Figure 1. In this physical model, $k$ and $c$ characteristics are a function of temperature, provided by a SMA helical coil spring.

The equation that governs the system defined in Figure 1 is given by [12]

$$
m \ddot{x}+c \dot{x}+k x=m_{d} e \omega^{2} \sin \omega t,
$$

where $m_{d}, e$, and $\omega$ are, respectively, the unbalanced mass, imposed eccentricity, and excitation frequency. Solving (1), the frequency response for this condition is given by

$$
\frac{m X}{m_{d} e}=\frac{r^{2}}{\sqrt{\left(1-r^{2}\right)^{2}+(2 \zeta r)^{2}}},
$$

where $r=\omega / \omega_{n}$ is the frequency ratio and $\zeta=c / c_{c}$ is the damping factor of the system [12].

Considering Figure 1 and a harmonic motion of the type $x=X e^{i \omega t}$, the force is given by the sequence of the following equations:

$$
\begin{aligned}
& F(t)=k x+c \dot{x}, \\
& F(t)=k X e^{i \omega t}+i c \omega X e^{i \omega t}, \\
& F(t)=(k+i \omega c) x .
\end{aligned}
$$

From (4), the concept of complex stiffness can be established as follows:

$$
\begin{gathered}
k\left(1+i \frac{c \omega}{k}\right), \\
k^{*}=k(1+i \eta) .
\end{gathered}
$$

Here $\eta$ is called the loss factor and $k^{*}$ is defined as complex stiffness of the SMA coil spring actuator. 
The imaginary part of the complex stiffness, in, corresponds to the energy dissipated in the system, since the loss factor can be written as defined in the following equation:

$$
\eta=\frac{c \omega}{k}
$$

The material loss factor can be determined by the equivalent viscous damping factor, $\zeta_{\text {eq }}$, which can be obtained by the relation of the logarithmic decrement for slightly damped systems:

$$
\begin{gathered}
\delta \cong 2 \pi \zeta_{\mathrm{eq}} \cong \pi \eta, \\
\zeta_{\mathrm{eq}} \cong \frac{\eta}{2}
\end{gathered}
$$

From (9), the relation between the damping factor $\zeta_{\text {eq }}$ and the loss factor $\eta$ is $\eta \cong 2 \zeta_{\mathrm{eq}}$.

\section{Thermomechanical Properties of the SMA Actuator}

3.1. Elastic Modulus and Loss Factor of the SMA Material. For the fabrication of the SMA coil spring, a NiTi wire with $2.02 \mathrm{~mm}$ in diameter supplied by Memory-Metalle (Germany) was employed. In order to eliminate some of the strain hardening of the supplied material, the NiTi SMA wire was annealed at $400^{\circ} \mathrm{C}$ for 30 minutes and cooled at room temperature. This heat treatment at a temperature lower than $650^{\circ} \mathrm{C}$ ensures a high elastic response of the manufactured NiTi spring, on the order of $40 \%$ of its undeformed length, even in the martensitic state. After this heat treatment, two specimens were removed to determine some thermomechanical properties of the SMA material.

The first sample with $1.5 \mathrm{~mm}$ in length and $0.0065 \mathrm{~g}$ was used to determine the phase transformation temperatures of the NiTi SMA wire by DSC (differential scanning calorimetry). The second sample with $31.2 \mathrm{~mm}$ in length and $0.663 \mathrm{~g}$ was used for two tests. In the first test, the sample was studied using a dynamic mechanical analyzer (DMA, model Q800, TA Instruments) at three different temperatures $\left(30^{\circ} \mathrm{C}, 50^{\circ} \mathrm{C}\right.$, and $70^{\circ} \mathrm{C}$ ) corresponding to regions with different crystalline phases (martensite, mixture, and austenite). These experiments were carried out in a single cantilever beam mode by applying a tip force with variable oscillating frequency ( 8 to $150 \mathrm{~Hz}$ ) for a constant amplitude deflection of $5 \mu \mathrm{m}$. The second experiment performed with the second sample was realized to verify the influence of the frequency on the stiffness (elastic modulus) and damping (Tan $\delta$ ) for a range of temperatures starting from $25^{\circ} \mathrm{C}$ to $100^{\circ} \mathrm{C}$, for four different frequencies $(1 \mathrm{~Hz}, 5 \mathrm{~Hz}, 10 \mathrm{~Hz}$, and $12 \mathrm{~Hz})$.

3.2. Mathematical Model for the Stiffness of the SMA Spring. In this work, the simplified mathematical Ikuta model [13] was adapted to describe the behavior of the theoretical stiffness of the SMA spring as a function of temperature and simulate the experimental results. The following equations represent, respectively, the stiffness behavior of the SMA spring during heating and cooling:

$$
\begin{aligned}
& k_{\mathrm{SMA}-A} \\
& =k_{\min }+\left(\left(k_{\max }-k_{\min }\right)-\frac{\left(k_{\max }-k_{\min }\right)}{1+e^{\left(\left(6,2 /\left(A_{F}-A_{S}\right)\right) \cdot\left(T \cdot\left(\left(A_{F}+A_{S}\right) / 2\right)\right)\right)}}\right),
\end{aligned}
$$

$k_{\mathrm{SMA}-M}$

$$
=k_{\min }+\left(\left(k_{\max }-k_{\min }\right)-\frac{\left(k_{\max }-k_{\min }\right)}{1+e^{\left(\left(6,2 /\left(M_{S}-M_{F}\right)\right) \cdot\left(T \cdot\left(\left(M_{F}+M_{S}\right) / 2\right)\right)\right)}}\right),
$$

where

$$
\begin{aligned}
& k_{\mathrm{SMA}-A} \text { is stiffness of SMA spring during heating; } \\
& k_{\mathrm{SMA}-M} \text { is stiffness of SMA spring during cooling; } \\
& k_{\min } \text { is minimum stiffness of SMA spring; } \\
& k_{\max } \text { is maximum stiffness of SMA spring; } \\
& M_{S} \text { is martensite start temperature; } \\
& M_{F} \text { is martensite final temperature; } \\
& A_{S} \text { is austenite starts temperature; } \\
& A_{F} \text { is austenite final temperature; } \\
& T \text { is spring temperature. }
\end{aligned}
$$

3.3. Damping Factor of the Mechanical System. The equivalent damping factor $\zeta_{\text {eq }}$ was calculated from the free vibration response of the mechanical system with the SMA spring subject to an input impulse given by an impact hammer (PCB Piezotronics; model 086C03). From this excitement was possible to obtain the envelope curve of exponential nature that involves the signal and characterizes the decay of displacements with time. For this, the method of logarithmic decrement was employed, calculating the ratio between two chosen signal amplitudes.

Previous studies $[14,15]$ show that the damping factor for SMA material is generally less than 0.1. In this case, the equation for calculating the damping factor by the method of logarithmic decrement can be simplified and used as defined by the following:

$$
\zeta=-\frac{1}{2 \pi n} \ln \left(\frac{A_{n}}{A_{1}}\right)
$$

where $n$ is the number of cycles, $A_{1}$ is the amplitude of the first cycle, and $A_{n}$ is the amplitude of $n$ cycle.

3.4. Forced Vibration Tests. Several tests were performed with the mechanical system subjected to a harmonic excitation in order to compare the response of the system when the SMA spring is in the martensitic phase $\left(25^{\circ} \mathrm{C}\right)$ and in the austenitic phase $\left(70^{\circ} \mathrm{C}\right)$.

The system was excited in frequency ranges corresponding to the two resonance frequencies (martensite and austenite phases). Analyzing the structural responses in the time 


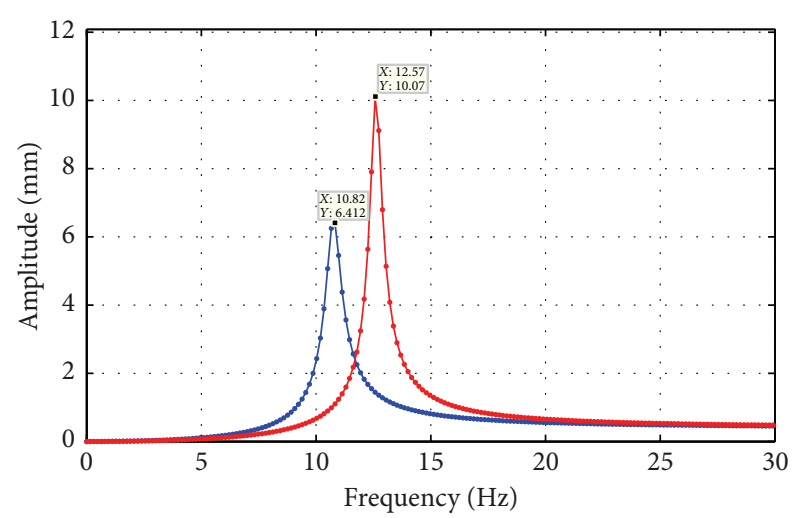

$\rightarrow$ Spring temperature $25^{\circ} \mathrm{C}$

$\rightarrow$ Spring temperature $70^{\circ} \mathrm{C}$

FIGURE 2: Typical frequency response for the system under unbalanced rotating.

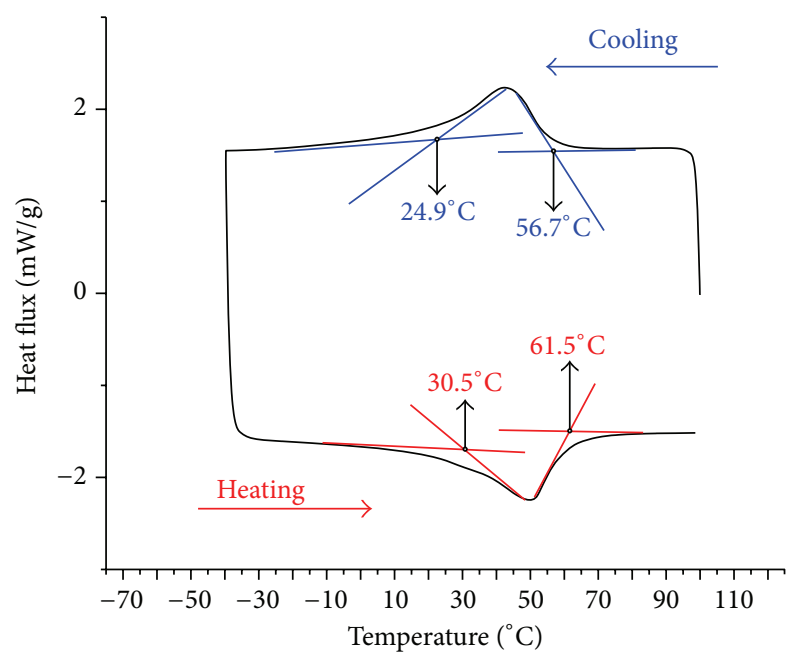

Figure 3: Transformation temperatures of the NiTi SMA wire obtained by DSC.

and frequency domains for these conditions, it was possible to analyze the system behavior and to better understand how variations of parameters of the SMA actuator affect the dynamic response of this typical mechanical model.

Figure 2 illustrates two typical frequency responses of the system with unbalanced rotating using physical parameters of the test bench. The blue curve represents the response with the SMA spring at $25^{\circ} \mathrm{C}$ (martensite phase), while the red curve represents the response with the SMA spring at $70^{\circ} \mathrm{C}$ (austenite phase). Two peaks corresponding to the natural frequencies and the influence of the stiffness and damping of the SMA spring on the dynamic behavior of the system can be verified. The heating process increases the stiffness of the NiTi SMA spring, causing an increase in frequency and reducing the damping (resulting in a peak of higher amplitude).

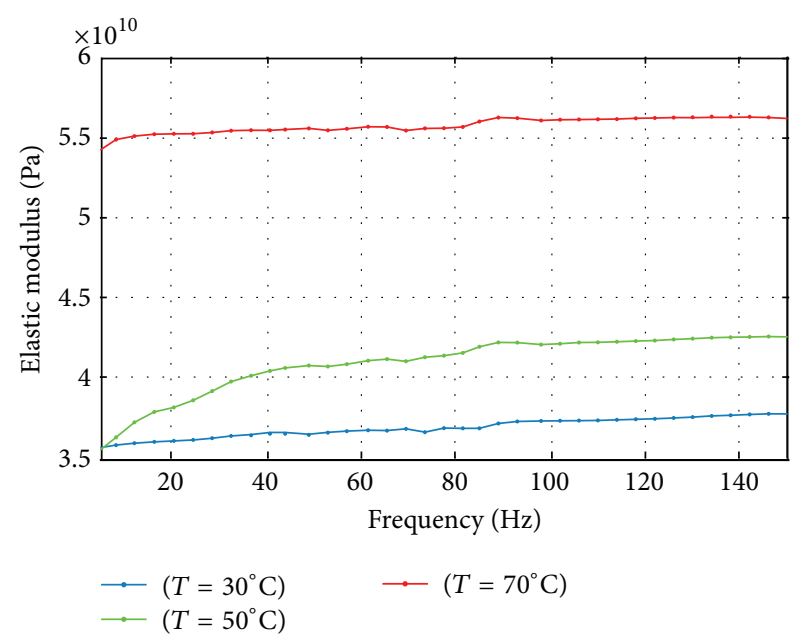

FIGURE 4: Elastic modulus as a function of frequency for the NiTi SMA wire at three temperatures: $30^{\circ} \mathrm{C}, 50^{\circ} \mathrm{C}$, and $70^{\circ} \mathrm{C}$.

\section{Results and Discussion}

4.1. Thermomechanical Characterization of the SMA Wire. The phase transformation temperatures were determined using a DSC calorimeter (TA Instruments; model Q20). The experiment was performed with a heating and cooling rate of $5^{\circ} \mathrm{C} / \mathrm{min}$ and a temperature range between $0^{\circ} \mathrm{C}$ and $100^{\circ} \mathrm{C}$. Figure 3 shows the characteristic DSC peaks for the NiTi SMA wire employed to manufacture the SMA spring actuator.

The phase transformation temperatures obtained were $M_{s}=56.7^{\circ} \mathrm{C}$ (martensite start) and $M_{f}=24.9^{\circ} \mathrm{C}$ (martensite finish) during cooling and $A_{s}=30.5^{\circ} \mathrm{C}$ (austenite start) and $A_{f}=61.5^{\circ} \mathrm{C}$ (austenite finish) during heating. Comparing the two temperatures of the DSC peaks, it can be verified that this NiTi SMA wire presents a low thermal hysteresis, of the order of $\Delta T=8^{\circ} \mathrm{C}$.

In parallel, two analyses of the dynamic behavior of the NiTi SMA wire were performed using a commercial DMA analyzer (TA Instruments; model Q800) in order to verify the influence of the excitation frequency and temperature on the elastic modulus and loss factor of the material. The results of these DMA tests with variable frequency are shown in Figures 4 and 5 .

The increase of temperature in Figure 4 changes significantly the elastic modulus, which showed values of about $36 \mathrm{GPa}\left(30^{\circ} \mathrm{C}\right), 41 \mathrm{GPa}\left(50^{\circ} \mathrm{C}\right)$, and $55 \mathrm{GPa}\left(70^{\circ} \mathrm{C}\right)$, taking as reference the frequency of $80 \mathrm{~Hz}$. The behavior of elastic modulus as a function of frequency showed small variations, mainly for the martensitic $\left(30^{\circ} \mathrm{C}\right)$ and austenitic $\left(70^{\circ} \mathrm{C}\right)$ stable states, with a tendency to stabilize above $100 \mathrm{~Hz}$.

The behavior of the loss factor was the inverse of the elastic modulus as pointed out in Figure 5. As expected [14], a reduction in the measured values with increasing temperature was verified. The damping in the austenitic phase $\left(70^{\circ} \mathrm{C}\right)$ is smaller than the values measured in the martensitic phase $\left(30^{\circ} \mathrm{C}\right)$. A variation of the loss factor was observed as 


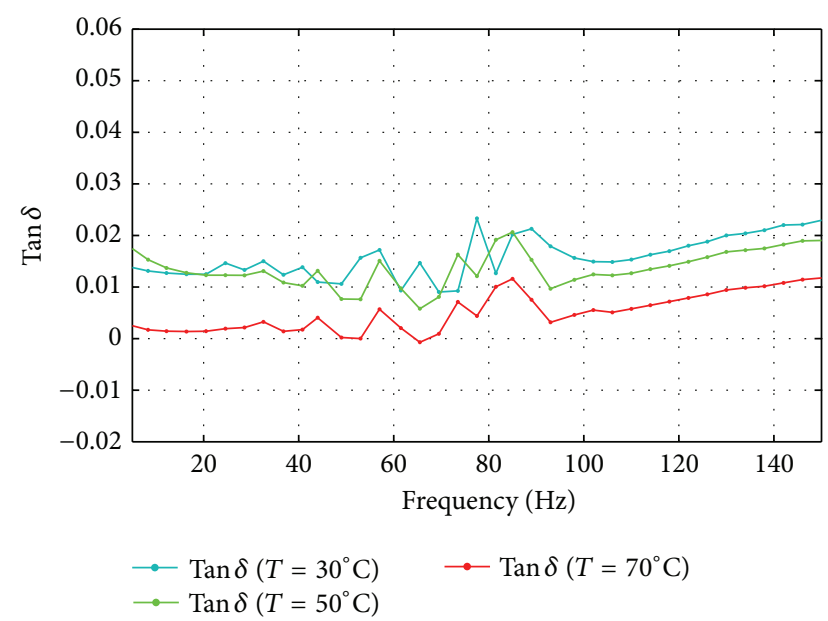

Figure 5: Loss factor as a function of frequency for the NiTi SMA wire at three temperatures: $30^{\circ} \mathrm{C}, 50^{\circ} \mathrm{C}$, and $70^{\circ} \mathrm{C}$.

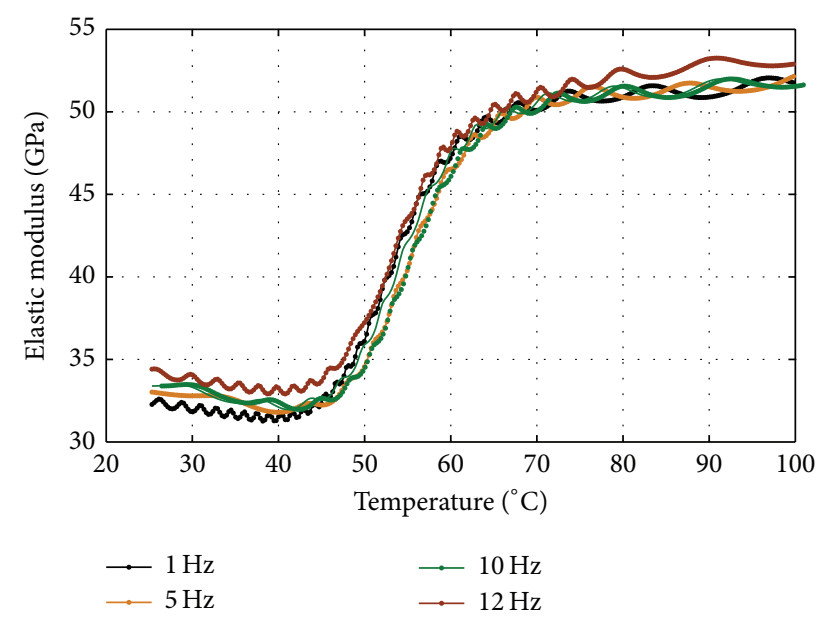

FIGURE 6: Behavior of the elastic modulus of the NiTi SMA wire with the change of excitation frequency.

a function of frequency with a tendency to increase linearly for frequencies higher than $100 \mathrm{~Hz}$.

Figures 6 and 7 show the characteristic curves for the NiTi SMA wire obtained with the DMA analyzer. The behavior of elastic modulus is not much affected by the frequency, being more dependent on the temperature. For example, in Figure 6 for martensitic state $\left(30^{\circ} \mathrm{C}\right)$ the elastic modulus increases of about $3 \mathrm{GPa}$ between $1 \mathrm{~Hz}$ and $12 \mathrm{~Hz}$. However, a considerable increase is observed in the elastic modulus for all frequencies along the phase transformation during heating. This increase of elastic modulus with temperature indicates a corresponding increase in the stiffness of the SMA material, resulting in less energy dissipation at high temperatures by the structure.

Figure 7 shows the behavior of the loss factor as a function of temperature and frequency. It is observed that the highest peaks of loss factor appear during the phase transformation

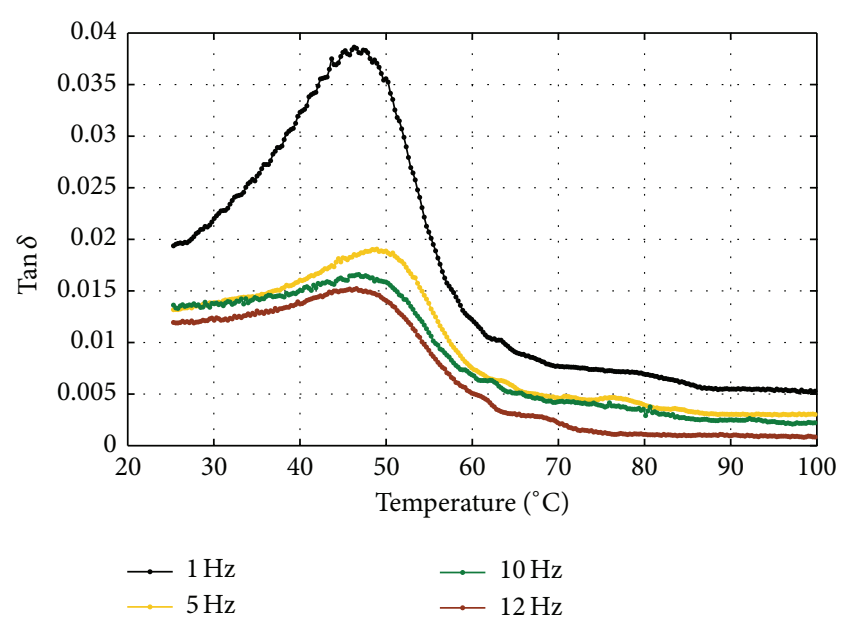

FIGURE 7: Behavior of the loss factor of the NiTi SMA wire with the change of excitation frequency.

for the lowest frequency $(1 \mathrm{~Hz})$. Higher excitation frequencies tend to inhibit the Tan $\delta$ peaks, so that for frequencies higher than $5 \mathrm{~Hz}$ peak values decrease rapidly.

The variation of stiffness and damping observed in Figures 6 and 7 is related to the internal movements of martensite variants into the SMA material, with lower stiffness and high damping in the martensitic phase compared to austenitic phase $[14,15]$.

4.2. Characterization of SMA Spring Stiffness. In order to stabilize the phase transformation of the SMA spring manufactured from the NiTi wire, a thermal cycling procedure was performed for training the spring actuator, as shown in Figure 8. In this procedure, 500 cycles of heating and cooling were performed in order to stabilize the behavior of shape memory effect of the SMA spring. In a training cycle, the NiTi SMA spring was heated to $80^{\circ} \mathrm{C}$ and then immediately cooled to $3^{\circ} \mathrm{C}$, under a constant load (dead weight).

For determining the SMA spring stiffness during heating and cooling, a universal testing machine (INSTRON 5582) equipped with a controlled heating chamber was used. For this one, the NiTi SMA spring was subjected to five cycles of compression loading and unloading, with $10 \mathrm{~mm}$ of maximum deflection in a temperature range between $25^{\circ} \mathrm{C}$ and $70^{\circ} \mathrm{C}$ in steps of $5^{\circ} \mathrm{C}$. For this imposed displacement the NiTi SMA spring presents an elastic response in both phases, martensite $\left(25^{\circ} \mathrm{C}\right)$ and austenite $\left(70^{\circ} \mathrm{C}\right)$, without presenting residual deformation. Table 1 shows the experimental results of stiffness and the theoretical stiffness obtained with the adapted Ikuta models (11) and (12).

Figure 9 shows the stiffness behavior of the NiTi SMA spring as a function of temperature. It can be verified that the stiffness increased 1.37 times at the end of heating when compared with the initial value. For temperatures higher than $60^{\circ} \mathrm{C}$ the stiffness tends to stabilize, due to the fact that from this point the crystalline structure of the SMA spring is fully austenitic. Similarly, stabilization of stiffness can be 
TABLE 1: Stiffness of the NiTi SMA spring actuator as a function of temperature.

\begin{tabular}{lcc}
\hline \multirow{2}{*}{ Temperature $\left({ }^{\circ} \mathrm{C}\right)$} & \multicolumn{2}{c}{ Stiffness $(\mathrm{N} / \mathrm{m})$} \\
\hline 25 & 2280.3 & Cooling \\
30 & 2337.1 & 2396.3 \\
35 & 2388.6 & 2382.5 \\
40 & 2502.6 & 2474.8 \\
45 & 2701.6 & 2654.1 \\
50 & 2897.2 & 2907.4 \\
55 & 3053.8 & 3044.7 \\
60 & 3083.1 & 3110.3 \\
65 & 3117.4 & 3128.4 \\
70 & 3134.5 & 3137.6 \\
\hline
\end{tabular}

TABLE 2: Main parameters of the experimental test bench.

\begin{tabular}{lc}
\hline Parameter & Value \\
\hline Total mass $(\mathrm{kg})$ & 0.4998 \\
Unbalanced mass $(\mathrm{kg})$ & 0.006 \\
Eccentricity $(\mathrm{m})$ & 0.033 \\
Spring material & NiTi SMA \\
Number of active coils & 7 \\
Undeformed spring length $(\mathrm{mm})$ & 34 \\
Spring wire diameter $(\mathrm{mm})$ & 2.02 \\
Spring effective diameter $(\mathrm{mm})$ & 12 \\
\hline
\end{tabular}

obtained at temperatures below $25^{\circ} \mathrm{C}$ when the SMA gets fully martensitic.

Comparing Figures 6 and 9 a qualitative similar behavior is observed between the pure elastic modulus of the NiTi SMA and stiffness of the smart spring as a function of temperature.

4.3. Test Bench: Specifications and Control System. The experimental set-up and fuzzy control system applied in this study was developed by Aquino [16] and subsequently used by Holanda [17]. This mass-spring system with 1 DOF is excited by an unbalanced motor assembled on an aluminum bar attached to the SMA spring. The mass is driven by two vertical rods assembled into a steel plate through two linear ball bearings. The rotational speed of the electrical motor was controlled with a frequency inverter that allows adjustment of the excitation in a range between 0 and $40 \mathrm{~Hz}$, including the two regions of resonances. Figure 10 shows the test bench developed for the experimental analysis.

Table 2 shows the specifications of the test bench showed in Figure 10. The experimental test bench is composed by (1) SMA spring; (2) unbalanced motor; (3) minicooler; (4) electrical heating system for SMA spring (Joule effect); (5) accelerometer; (6) impact hammer; (7) LabVIEW Interface.
The block diagram for temperature control of the NiTi SMA spring is shown in Figure 11. The controller aims to send information that will allow the activation of SMA actuator by changing its temperature. The heating of the SMA spring is realized in order to change the stiffness and consequently change the natural frequency causing the system to leave the resonance condition, leading to vibration reduction. The temperature control of the NiTi SMA spring is based on a fuzzy controller implemented in the LabVIEW software. The heating was done by Joule effect and the cooling was done by forced convection. The developed controller was not able to carry out a temperature sweep considering, for example, a sinusoidal temperature change. In this case, the user indicated the desired temperature and the controller is in charge of taking the system to that temperature and to keep it constant. Figure 12 shows the system actuation for temperature control of the NiTi SMA spring. A good performance of the temperature control can be observed, both for heating and cooling, with temperature stabilization of the SMA spring according to the reference temperature.

4.4. Free Vibration Response. Figures 13 and 14 show the exponential decay of the system with SMA spring in two selected conditions: $25^{\circ} \mathrm{C}$ and $70^{\circ} \mathrm{C}$, respectively.

The damping transfered to the system by the SMA spring is a function of temperature. For $25^{\circ} \mathrm{C}$ the damping factor $\left(\zeta_{\text {eq }}\right)$ measured was 0.0303 , while for SMA spring at $70^{\circ} \mathrm{C}$ the obtained value was 0.0194 . In the condition of Figure 13 the damping of the SMA spring is higher, and consequently the decay of the displacements is faster than that found in Figure 14. For the stiffness test and using the same temperature range, the results shown in Figure 15 were obtained, with the values of the damping factor of the system of Table 3.

By analyzing Figure 15, it can be observed that the damping peaks appear during the phase transformation, between $40^{\circ} \mathrm{C}$ and $45^{\circ} \mathrm{C}$. At these temperatures, the measured damping factors were 0.0327 and 0.0324 , respectively. The minimum damping was verified at the austenitic phase $\left(70^{\circ} \mathrm{C}\right)$, with the value of 0.0194 . In the martensitic phase, the damping factor measured was 0.0303 .

The qualitative behavior of the damping factor shown in Figure 15 is similar to the one of Tan $\delta$ for the SMA wire measured in the DMA, as pointed out in Figure 7. The damping peak verified during phase transformation is observed mainly due to the transient character of this region, which is related to accommodation of austenite-martensite variants during thermally induced transformation.

4.5. Vibration Response with Temperature Control in the Resonance Condition. In order to verify the reduction in the amplitude of resonance for the two conditions of SMA spring (martensite and austenite phases), the mechanical system was excited in the natural frequency and then the temperature control was activated, heating or cooling the SMA spring.

In the first test, the system was put in resonance with the SMA spring at $25^{\circ} \mathrm{C}$ (blue curve) and then heated to $70^{\circ} \mathrm{C}$ (red curve). Figure 15 shows the time response for that test 


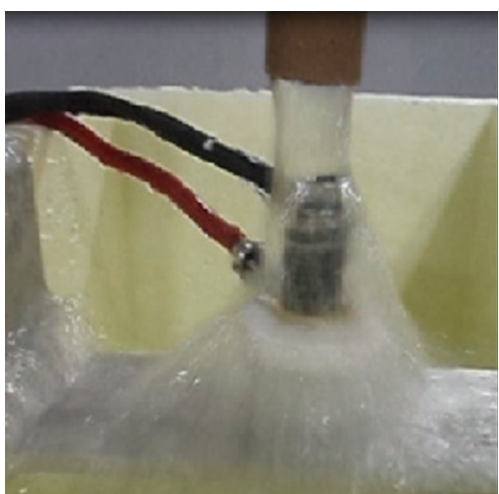

(a)

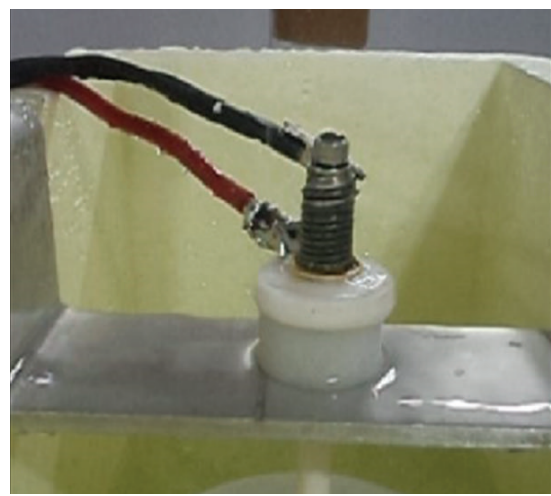

(b)

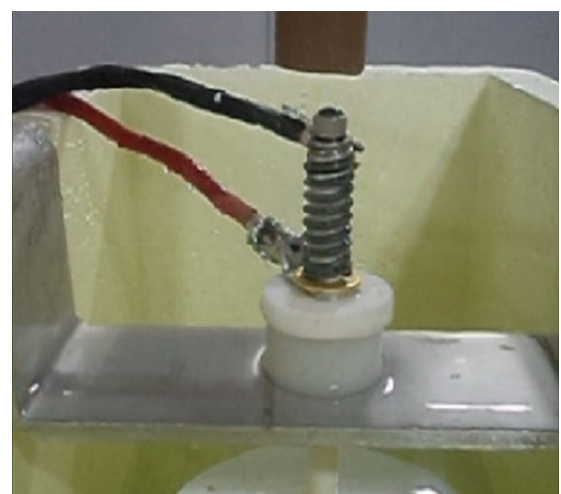

(c)

FIGURE 8: Details of thermomechanical cycling for training the NiTi SMA spring. (a) Cooling $\left(\sim 3^{\circ} \mathrm{C}\right)$; (b) delay; (c) heating by electrical current $\left(\sim 80^{\circ} \mathrm{C}\right)$.

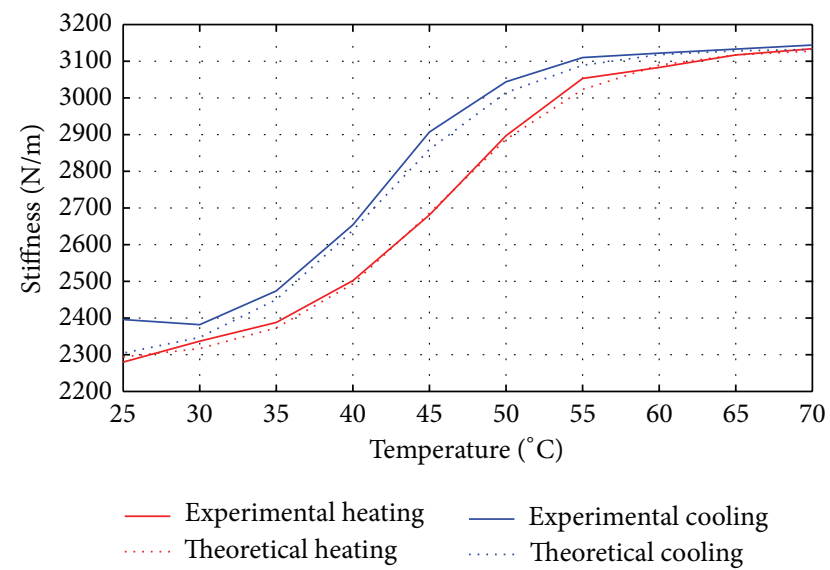

Figure 9: Theoretical and experimental stiffness of the NiTi SMA spring as a function of temperature.

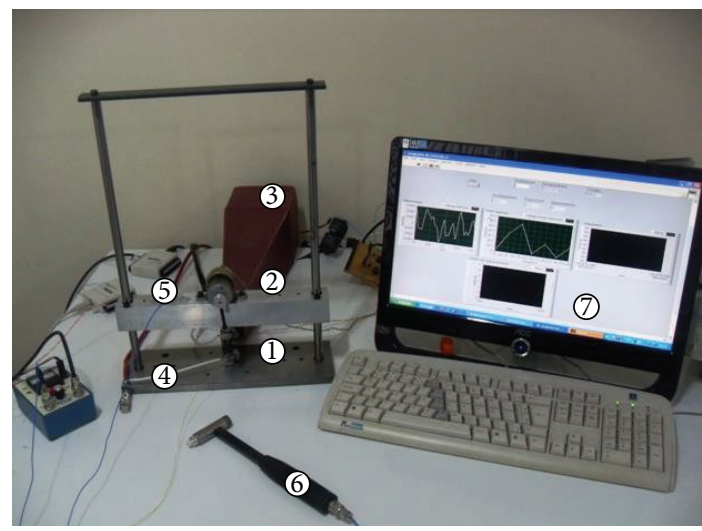

FIGURE 10: Experimental test bench: (1) SMA spring; (2) unbalanced motor; (3) minicooler; (4) electrical heating system (Joule effect); (5) accelerometer; (6) impact hammer; (7) LabVIEW Interface. condition. In the blue range of Figure 16 the maximum amplitude was $6 \mathrm{~mm}$. After heating, the system got out of resonance with maximum amplitudes of $2.7 \mathrm{~mm}$, corresponding to $55 \%$ of reduction in the displacement levels. These amplitudes are lower than $10 \mathrm{~mm}$, which was the displacement imposed for SMA spring in elastic regime during the thermomechanical characterization of stiffness as a function of temperature (Table 1, Figure 9).

In the second test, the system was put in resonance with the SMA spring at $70^{\circ} \mathrm{C}$ (red curve) and then cooled to $25^{\circ} \mathrm{C}$ (red curve). Figure 17 shows the time response for that test condition. In the blue range of Figure 17 the maximum amplitude was $12 \mathrm{~mm}$. After heating, the system got out of resonance with maximum amplitudes of $5.7 \mathrm{~mm}$, corresponding to $60 \%$ of reduction in the displacement levels. Typically, the linear region of a superelastic NiTi spring corresponds to about $40 \%$ of its undeformed length, as can be seen in the work of Aguiar et al. [7]. Then, as the amplitude of vibration did not exceed $35 \%$ of the undeformed spring length, it is estimated that there is no energy dissipation in the system due to a possible stress-induced phase transformation in the SMA spring. To make this hysteretic dissipation occurs it is necessary to achieve much higher strain levels in the SMA spring.

Figure 18 shows the vibration levels measured when the system is put into resonance at three different temperatures. With increasing temperature and variation of damping of the system, the amplitudes change. The damping is higher in the martensitic phase, showing a slight peak in the region of phase transformation, and is minimal in the austenite phase, as pointed out in Figure 7. These characteristics can be noted when considering the amplitude of vibrations at the resonance zones. Lower amplitudes are observed at $45^{\circ} \mathrm{C}$, temperature where the maximum damping occurs. At $70^{\circ} \mathrm{C}$, the amplitudes are higher than the ones measured previously due to the lower damping of the SMA spring in this temperature range $\left(25^{\circ} \mathrm{C}\right.$ to $\left.45^{\circ} \mathrm{C}\right)$. These amplitude signals were collected separately, placing the system in resonance for each temperature examined. 


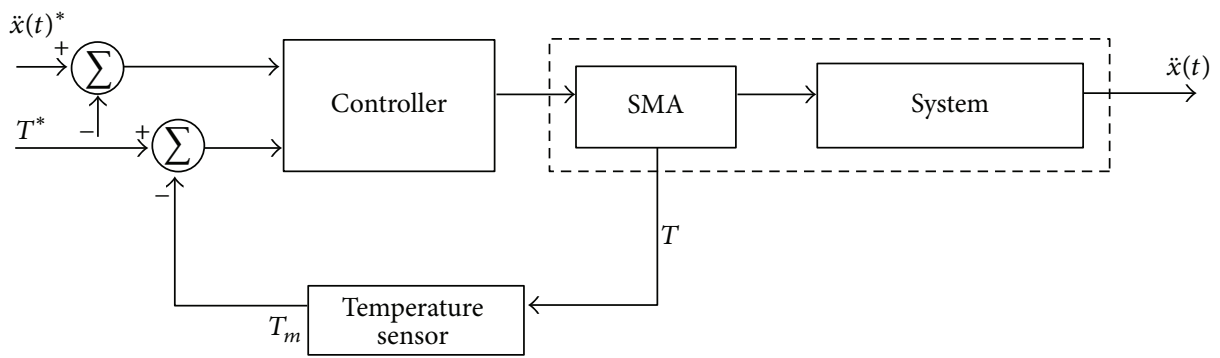

FIGURE 11: Representation of the temperature control system for the SMA spring actuator.

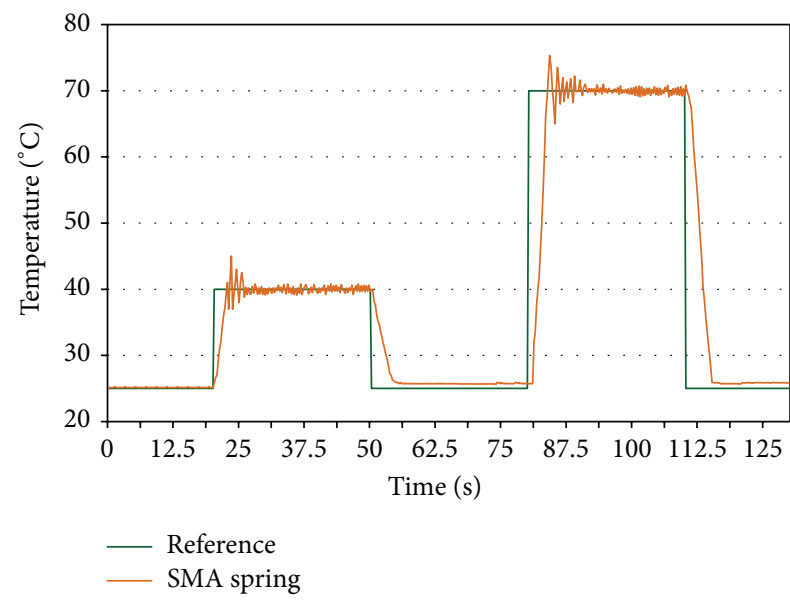

Figure 12: Performance of the temperature control system for the SMA spring.

TABLE 3: Experimental damping factor of the mechanical system as a function of temperature.

\begin{tabular}{lcc}
\hline \multirow{2}{*}{ Temperature $\left({ }^{\circ} \mathrm{C}\right)$} & \multicolumn{2}{c}{ Damping factor $\zeta_{\text {eq }}$} \\
& Heating & Cooling \\
\hline 25 & 0.03037 & 0.02976 \\
30 & 0.03096 & 0.03091 \\
35 & 0.03124 & 0.03158 \\
40 & 0.03179 & 0.03277 \\
45 & 0.03241 & 0.03054 \\
50 & 0.02823 & 0.02669 \\
55 & 0.02465 & 0.02293 \\
60 & 0.02048 & 0.02069 \\
65 & 0.02027 & 0.02047 \\
70 & 0.01947 & 0.02013 \\
\hline
\end{tabular}

Table 4 allows verification of the validity of the relationship between the loss factor and the damping factor, $\eta=$ $2 \zeta_{\text {eq }}$. As this relationship is valid only when the system is in resonance, the loss factor (14) of the NiTi SMA spring was calculated from the simplification of (13), considering

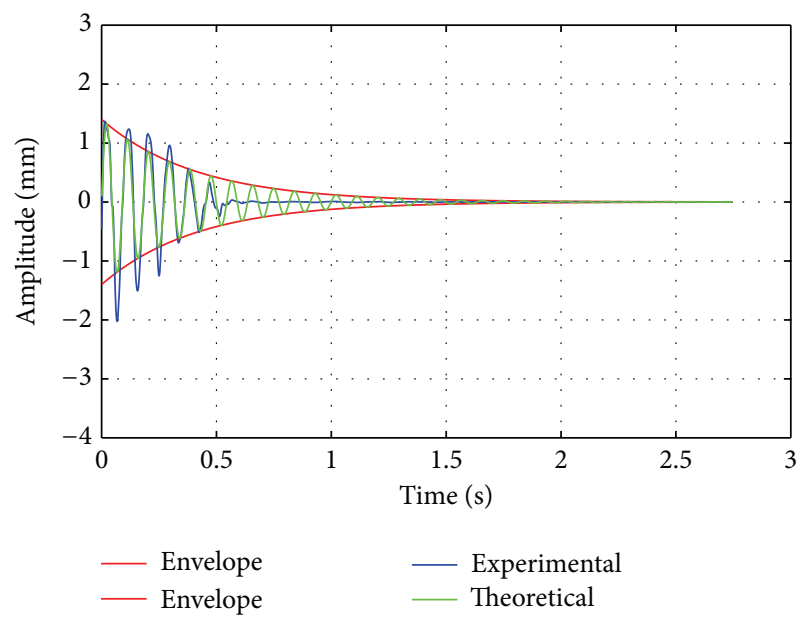

FIGURE 13: Impulse response of the mechanical system at $25^{\circ} \mathrm{C}$.

TABLE 4: Relationship between damping factor and loss factor for the resonance condition.

\begin{tabular}{lcc}
\hline Temperature $\left({ }^{\circ} \mathrm{C}\right)$ & $2 *$ damping factor $\left(2 \zeta_{\mathrm{eq}}\right)$ & Loss factor $\eta$ \\
\hline 25 & 0.06074 & 0.07204 \\
30 & 0.06192 & 0.07265 \\
35 & 0.06248 & 0.07529 \\
40 & 0.06358 & 0.07643 \\
45 & 0.06482 & 0.07635 \\
50 & 0.05646 & 0.05988 \\
55 & 0.0493 & 0.05043 \\
60 & 0.04096 & 0.04268 \\
65 & 0.04054 & 0.03810 \\
70 & 0.03894 & 0.03385 \\
\hline
\end{tabular}

the ratio of frequency equal to 1 (in resonance condition). Consider

$$
\begin{gathered}
X=\frac{F_{0} / k}{\sqrt{\left(1-r^{2}\right)^{2}+(2 \zeta r)^{2}}}, \\
\eta=\frac{F_{0} / k}{X} .
\end{gathered}
$$




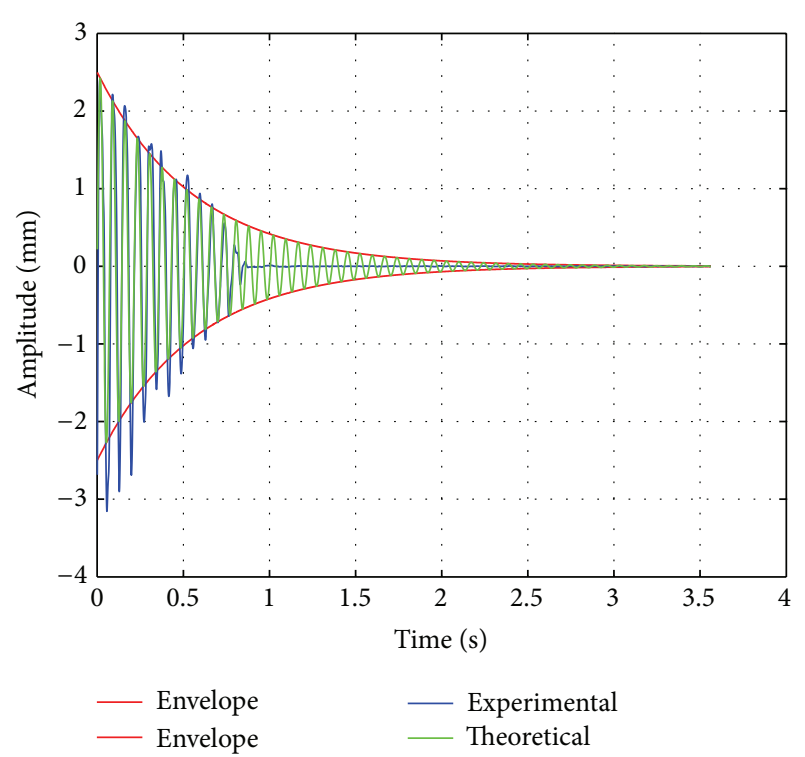

FIGURE 14: Impulse response of the mechanical system at $70^{\circ} \mathrm{C}$.

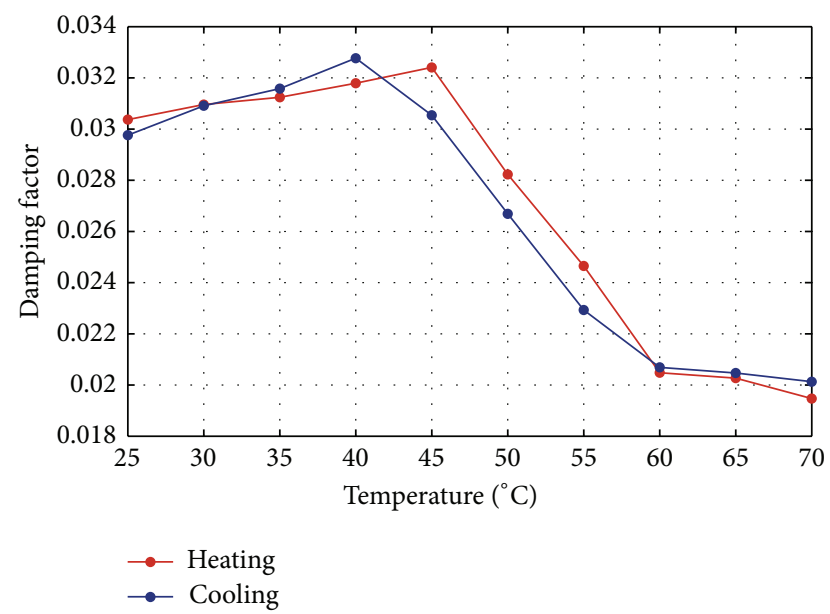

FIGURE 15: Damping factor of the mechanical system as a function of temperature.

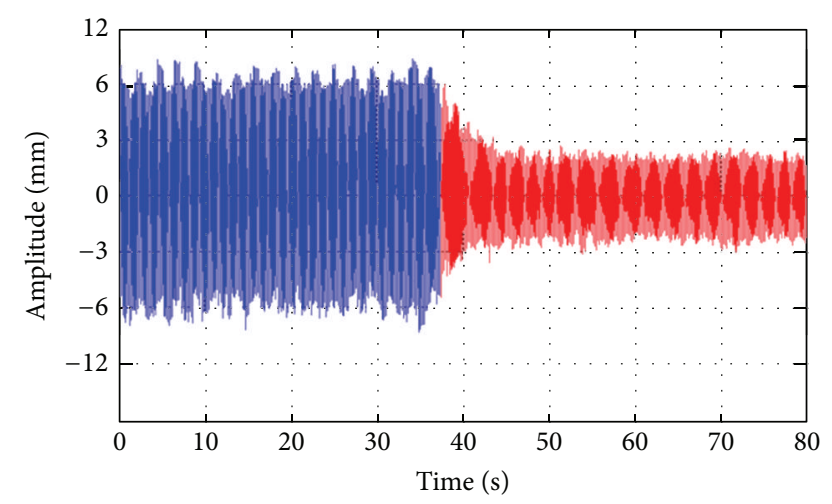

FIGURE 16: Time response of the mechanical system in the resonance condition with temperature variation and SMA spring initially in the martensitic phase (blue curve; $f_{n}=10.83 \mathrm{~Hz}$ ).

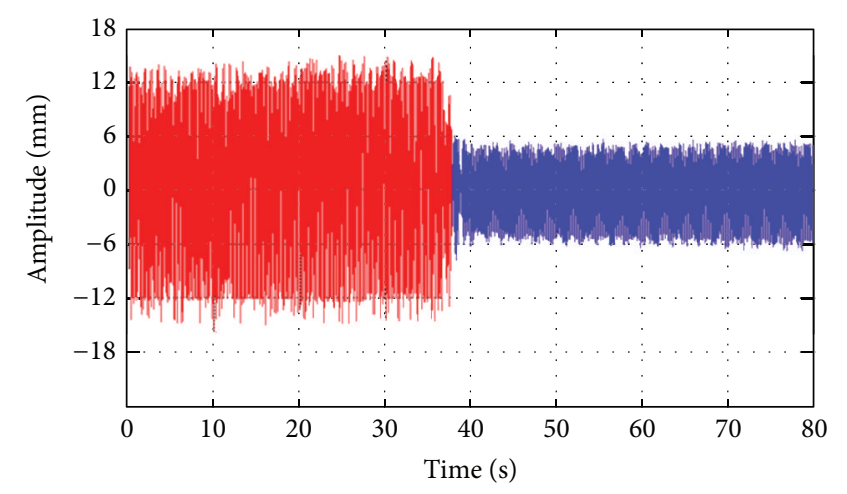

FIGURE 17: Time response of the mechanical system in the resonance condition with temperature variation and SMA spring initially in the austenitic phase (red curve; $f_{n}=12.70 \mathrm{~Hz}$ ).

Figure 19 represents graphically the values of damping factor and loss factor of Table 4. Therefore, it is possible to validate the relationship between the loss factor and the damping factor defined by (10). In this case, errors smaller than $12 \%$ were verified.

\section{Conclusions}

This paper investigated the thermomechanical characterization of a shape memory alloy coil spring actuator, as well as its application as vibration attenuator in a mass-spring system with single degree of freedom. The main conclusions that can be outlined from the obtained results are the following:

(i) The elastic modulus of the NiTi SMA wire increases slightly with frequency. Furthermore, the modulus increases significantly during phase transformation, verifying the influence of a temperature increasing. At about of $60 \%$ of the elastic modulus increasing was observed when comparing the values of the martensitic phase with the austenitic phase.

(ii) By the DMA analysis it was observed that increasing the excitation frequency of the NiTi SMA wire leads to a decay of the damping capacity (Tan $\delta$ ), much due to decreased mobility in the crystalline structure.

(iii) The experimental SMA spring stiffness showed good agreement with the behavior estimated by the theoretical model proposed by Ikuta et al. [13]. The stiffness of the SMA spring at the austenitic phase (hot) became 1.37 times higher than in the martensitic phase (cool).

(iv) The damping factor of the system measured experimentally shows a maximum value at the martensitic region (cool) and a minimum at the austenitic phase (hot). The behavior of the damping is the opposite of the stiffness and each of these parameters interferes differently in the dynamic response of the mechanical system.

(v) The system showed distinct dynamic responses in the different temperatures studied. With the SMA spring at $25^{\circ} \mathrm{C}$ the natural frequency of the system was 

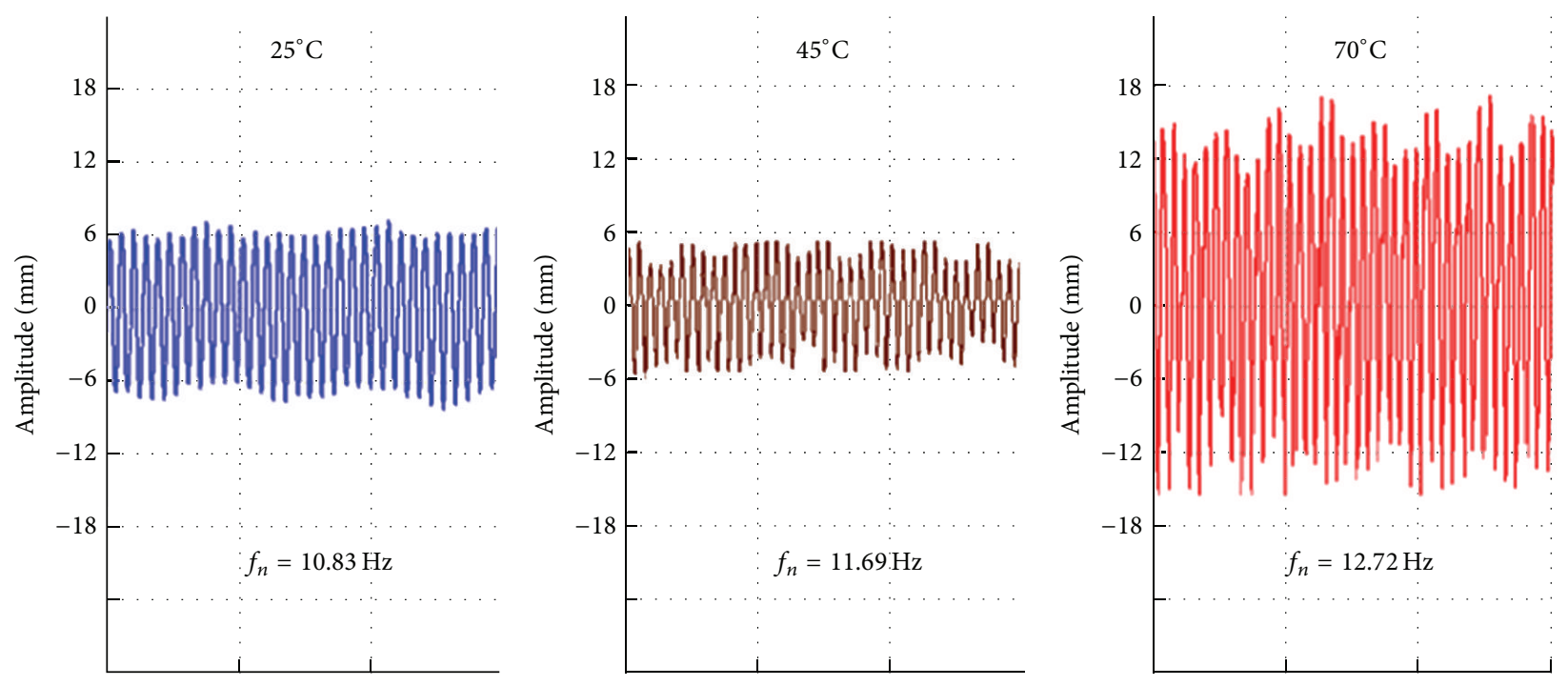

FIGURE 18: Time response of the mechanical system in resonance for the SMA spring at three temperatures.

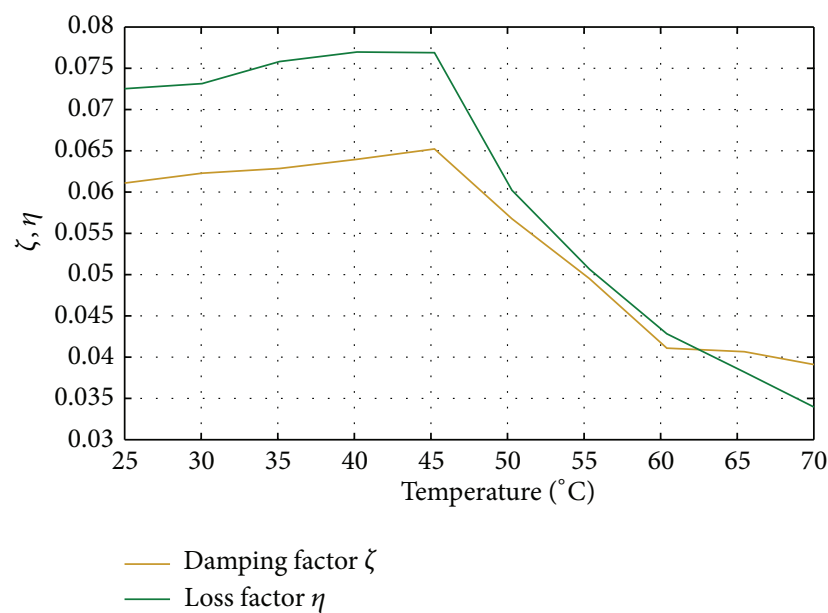

FIGURE 19: Loss factor and damping factor of the mechanical system as a function of temperature.

$10.8 \mathrm{~Hz}$ with maximum amplitudes levels of $6 \mathrm{~mm}$. At this temperature the SMA spring presents smaller stiffness and higher damping when compared with the properties of the SMA spring at $70^{\circ} \mathrm{C}$. In this last condition the resonance frequency shifted to $12.7 \mathrm{~Hz}$ and the maximum amplitude of displacement peaks reached $12 \mathrm{~mm}$.

(vi) Analyzing the system responses in the time and frequency domains was possible to prove the validity of the relationship between the damping factor $2 \zeta_{\mathrm{eq}}$ and the loss factor $\eta$. There is a good agreement between the theoretical formulation and experimental procedure employed.

\section{Conflict of Interests}

The authors declare that there is no conflict of interests regarding the publication of this paper.

\section{Acknowledgments}

The authors would like to acknowledge the CNPq Brazilian research agency for funding the following projects: National Institute of Science and Technology-Smart Structures in Engineering (Grant 574001/2008-5), Casadinho UFCG-UFRJ-ITA (Grant 552199/2011-7), Universal 14/2012 (Grant 474524/2012-4), and PQ2 (Grant 302320/2011-3).

\section{References}

[1] Y. J. Yan and L. H. Yam, "A synthetic analysis on design of optimum control for an optimized intelligent structure," Journal of Sound and Vibration, vol. 249, no. 4, pp. 775-784, 2002.

[2] D. C. Lagoudas, Shape Memory Alloys: Modeling and Engineering Applications, Springer, New York, NY, USA, 2008.

[3] M. Yuvaraja and M. Senthil Kumar, "Experimental studies on SMA spring based dynamic vibration absorber for active vibration control," European Journal of Scientific Research, vol. 77, no. 2, pp. 240-251, 2012.

[4] M. M. Barzegari, M. Dardel, A. Fathi, and M. H. Pashaei, "Effect of shape memory alloys wires on natural frequency of plates," Journal of Mechanical Engineering and Automation, vol. 2, no. 1, pp. 23-28, 2012.

[5] R. A. A. Aguiar, M. A. Savi, and P. M. C. L. Pacheco, "Experimental investigation of vibration reduction using shape memory alloys," Journal of Intelligent Material Systems and Structures, vol. 24, no. 2, pp. 247-261, 2013.

[6] R. A. A. de Aguiar, W. C. de Castro Leão Neto, M. A. Savi, and P. M. Calas Lopes Pacheco, "Shape memory alloy helical springs performance: modeling and experimental analysis," Materials Science Forum, vol. 758, pp. 147-156, 2013. 
[7] R. A. A. Aguiar, M. A. Savi, and P. M. C. L. Pacheco, "Experimental and numerical investigations of shape memory alloy helical springs," Smart Materials and Structures, vol. 19, no. 2, Article ID 025008, 2010.

[8] M. A. Savi, A. S. De Paula, and D. C. Lagoudas, "Numerical investigation of an adaptive vibration absorber using shape memory alloys," Journal of Intelligent Material Systems and Structures, vol. 22, no. 1, pp. 67-80, 2011.

[9] W. Rackza, "Testing of a spring with controllabe stiffness," Mechanics, vol. 25, no. 2, pp. 79-86, 2006.

[10] R. Mirzaeifar, R. Desroches, and A. Yavari, "A combined analytical, numerical, and experimental study of shape-memory-alloy helical springs," International Journal of Solids and Structures, vol. 48, no. 3-4, pp. 611-624, 2011.

[11] Y. Toi, J.-B. Lee, and M. Taya, "Finite element analysis of superelastic, large deformation behavior of shape memory alloy helical springs," Computers and Structures, vol. 82, no. 20-21, pp. 1685-1693, 2004.

[12] D. J. Inman, Engineering Vibration, Prentice Hall, 2nd edition, 2000.

[13] K. Ikuta, M. Tsukamoto, and S. Hirose, "Mathematical model and experimental verification of shape memory alloy for designing micro actuator," in Proceedings of the IEEE Micro Electro Mechanical Systems (MEMS '91), pp. 103-108, February 1991.

[14] N. J. Da Silva, E. N. D. Grassi, and C. J. De AraúJo, "Dynamic properties of NiTi shape memory alloy and classic structural materials: a comparative analysis," Materials Science Forum, vol. 643, pp. 37-41, 2010.

[15] J. San Juan and M. L. Nó, "Damping behavior during martensitic transformation in shape memory alloys," Journal of Alloys and Compounds, vol. 355, no. 1-2, pp. 65-71, 2003.

[16] A. S. Aquino, Controle de vibração de um sistema sob desbalanceamento rotativo utilizando atuador de liga com memória de forma [Ph.D. thesis], Universidade Federal da Paraíba, João Pessoa, Brazil, 2011.

[17] S. A. Holanda, Estudo da rigidez complexa de um sistema vibratório incorporando atuador com memória de forma [M.S. thesis], Universidade Federal de Campina Grande, Campina Grande, Brazil, 2013. 

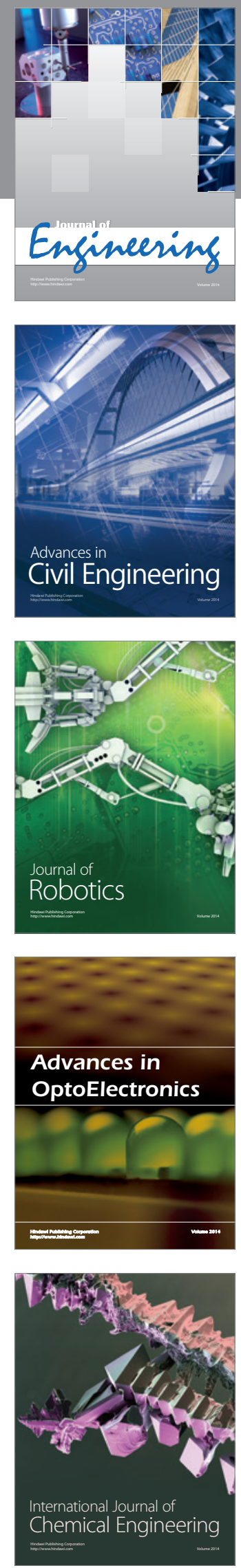

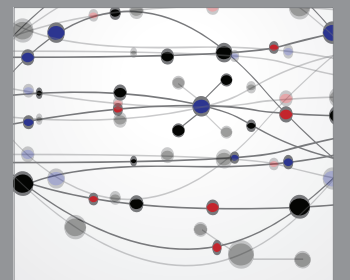

The Scientific World Journal
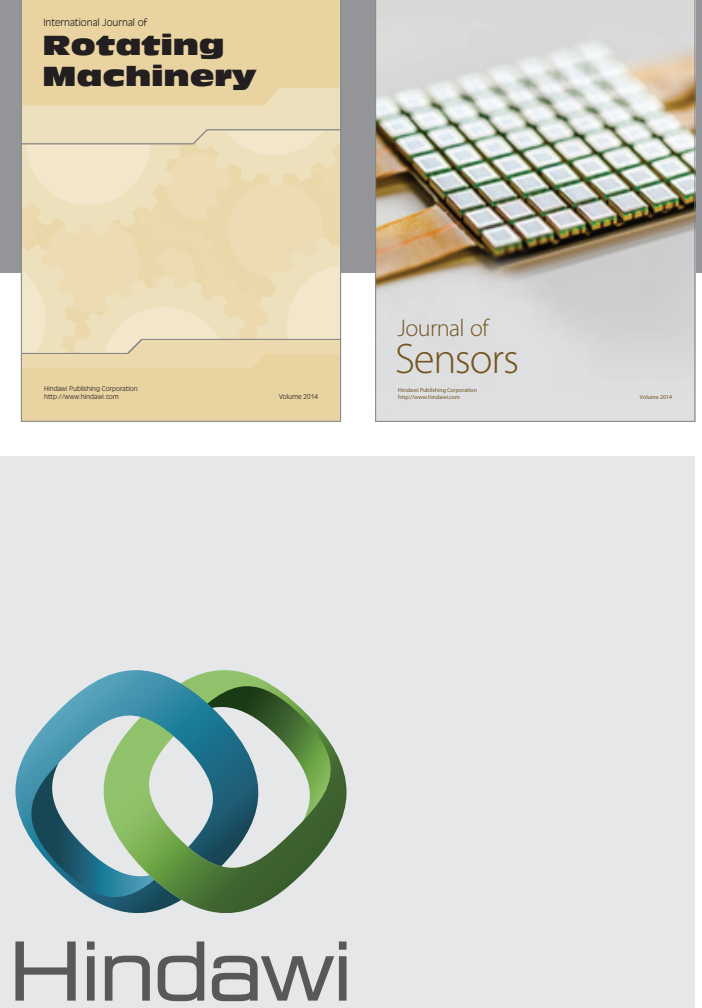

Submit your manuscripts at http://www.hindawi.com
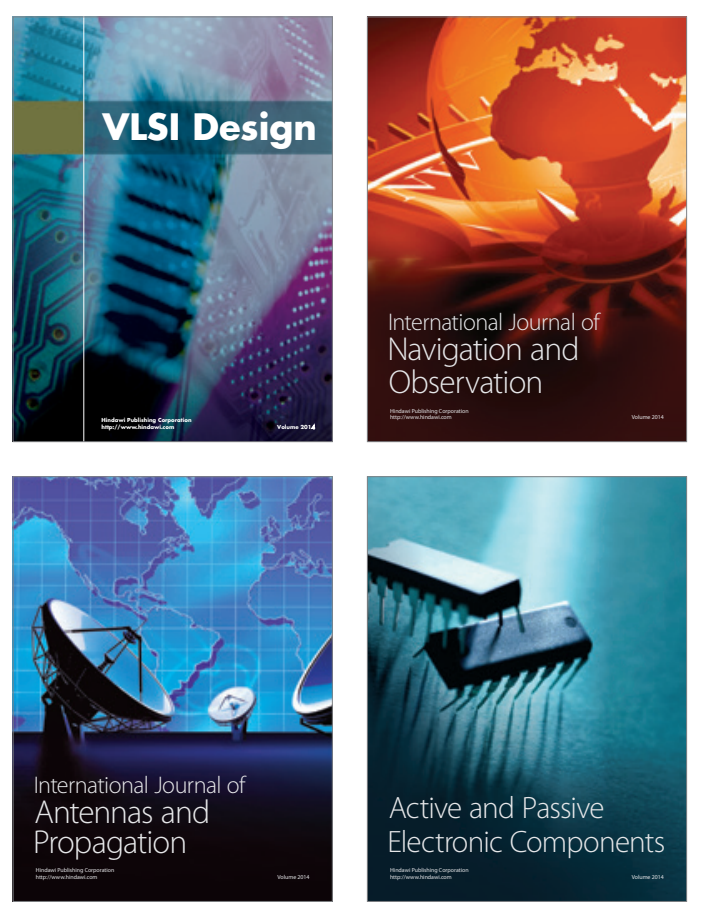
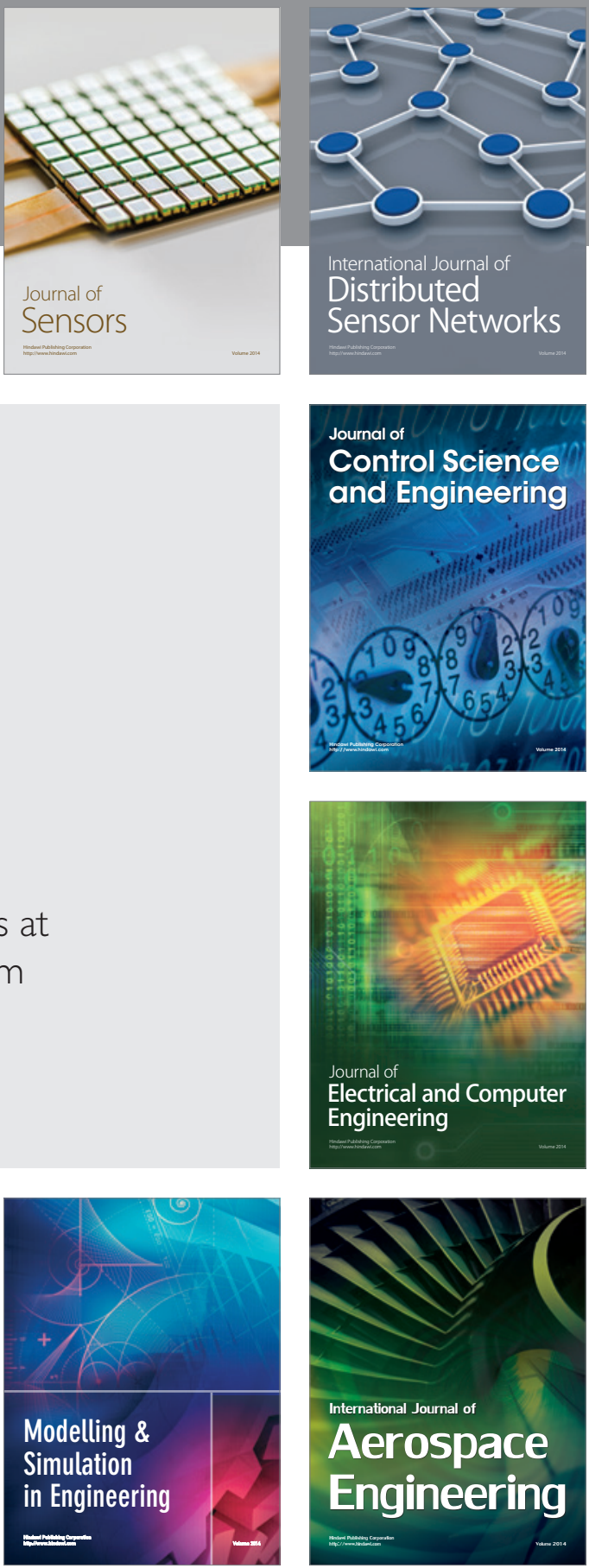

Journal of

Control Science

and Engineering
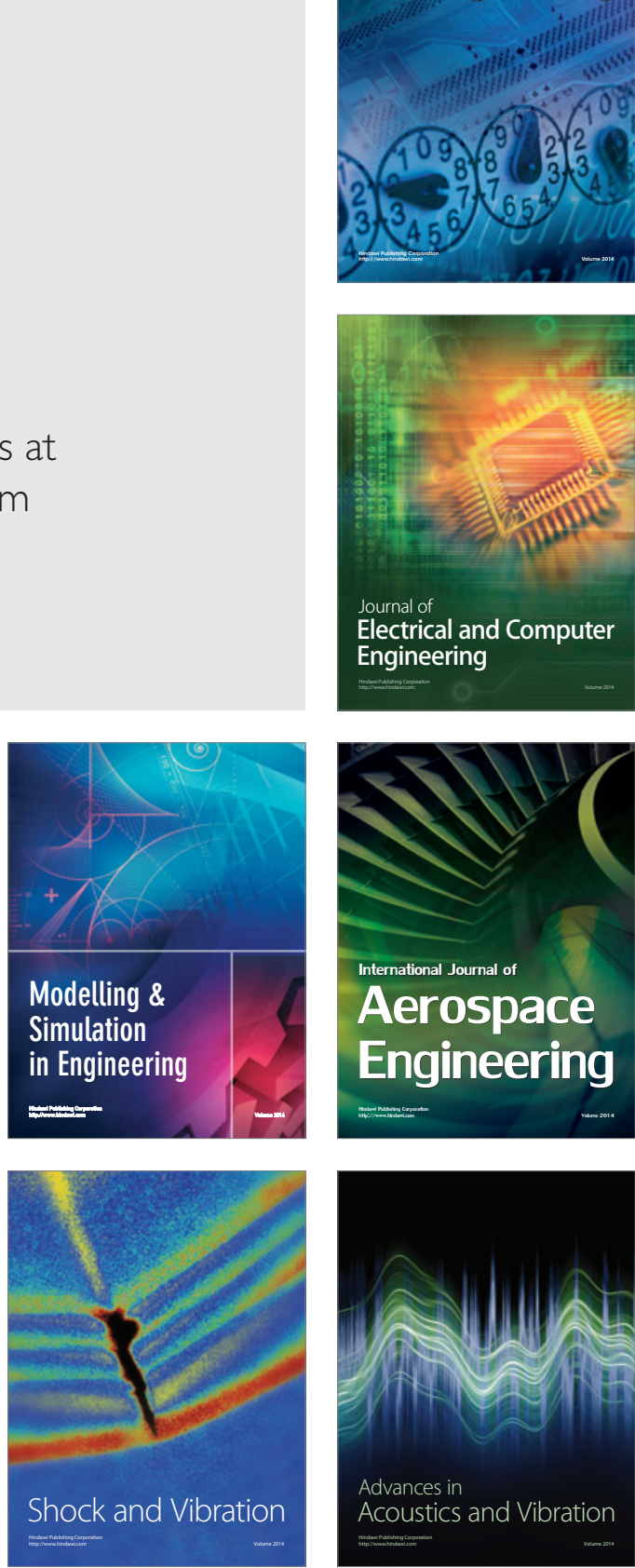